\title{
REVISTAMARACANAN
}

Dossiê

\section{O RELATO COMO VINGANÇA: as memórias de Stanislaw Szmajzner}

\author{
NARRATION AS REVENGE: the memories of Stanislaw Szmajzner
}

\author{
Felipe Cittolin Abal \\ Universidade de Passo Fundo \\ felipe.c.abal@hotmail.com
}

\begin{abstract}
Resumo: O artigo analisa o livro Inferno em Sobibor: a tragédia de um adolescente judeu de Stanislaw Szmajzner, ex-prisioneiro do campo de extermínio de Sobibor na Polônia que, posteriormente, passou a residir no Brasil onde publicou suas memórias. Através da leitura do texto procura-se verificar a forma como é construída esta obra autobiográfica com base nas memórias de um sobrevivente de um campo de extermínio durante a Segunda Guerra Mundial, identificando as suas características e os atritos existentes entre o relato e outras fontes. O livro de Szmajzner se encaixa no que Todorov estabeleceu como bom uso da memória, uma vez que utiliza o caso exemplar do autor para gerar uma lição, buscando impedir que casos análogos venham a se repetir no futuro, além de se estabelecer como um instrumento para que os crimes cometidos pelos algozes do autor não sejam esquecidos, utilizando a obra como uma forma de vingança.
\end{abstract}

Palavras-chave: Autobiografia; Inferno em Sobibor; Genocídio; Memória.

Abstract: This article analyzes the book Hell in Sobibor: the tragedy of a Jewish teenager by Stanislaw Szmajzner, a former prisoner in the Nazi extermination camp in Sobibor that latter resided in Brazil where he published his memoirs. Based on the reading of the text we aim to verify how this autobiographical work is constructed based on the memory of a survivor of an extermination camp during World War II, identifying its characteristics and frictions between the report and other sources. Szmajzner's book fits in what Todorov established as good use of the memory, since the exemplar case of the author is used to generate a lesson, intended to prevent that analog cases occur in the future. Also, the book is established as an instrument so that the crimes committed by the tormentors of the author are not forgotten, using the work as a form of revenge.

Keywords: Autobiography; Hell in Sobibor; Genocide; Memory.

Artigo recebido para publicação em: Setembro de 2016

Artigo aprovado para publicação em: Dezembro de 2016 


\title{
Introdução
}

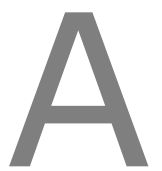

primeira vez que me deparei com o nome Stanislaw Szmajzner foi quando realizava uma pesquisa a respeito de dois criminosos nazistas que haviam sido encontrados no Brasil e cujos pedidos de extradição foram julgados pelo Supremo Tribunal Federal. Sua imagem, primeiramente, era a de um jovem apelidado singelamente de Shlomo que através de sua perspicácia conseguiu sobreviver a uma das mais nefastas criações da modernidade: o campo de extermínio. Posteriormente, esse jovem se metamorfoseou em minha mente no Sr. Szmajzner, um sobrevivente, um relator dos horrores do genocídio judeu, uma pessoa que, devido às suas vivências, merece o maior respeito possível, e devo esclarecer já neste momento que é esta imagem que, para mim, seu nome ainda traz.

Dessa maneira, escrever a respeito de sua obra autobiográfica se traduz em um desafio, uma vez que após mais de quatro anos de pesquisas que, direta ou indiretamente, tratam sobre o genocídio judeu durante a Segunda Guerra Mundial, cria-se uma cumplicidade entre o pesquisador, aqueles que foram vítimas das agressões nazistas e os seus relatos. Nesse sentido já alertou Cláudio Elmir:

\begin{abstract}
O interessante, parece-me, é pensar na hipótese de que os relatos de memória literariamente mais sofisticados sejam, por esta razão, capazes de embotar, pela sedução produzida em seu leitor, o ponderado e cuidadoso escrutínio do texto. Neste jogo entre o texto e o leitor, ainda que este último se coloque, costumeiramente, no papel de crítico do testemunho no seu oficio, a "suspensão da descrença" - regra de leitura própria da produção oriunda do campo literário - encontra, involuntária e paradoxalmente, a sua realização por meio dos "especialistas". Nestes casos, imperativos morais, ideológicos ou politicos talvez sejam responsáveis por uma espécie de "comunhão afetiva" entre o historiador e a sua "fonte". ${ }^{1}$ (Grifos do autor)
\end{abstract}

Ciente desse desafio de distanciar-se do objeto da pesquisa e alertado o leitor a esse respeito, é trazido este artigo com o objetivo de discorrer a respeito da narrativa proposta por Stanislaw Szmajzner em seu livro autobiográfico Inferno em Sobibor: a tragédia de um adolescente judeu, buscando, através de aparatos teóricos trazidos especialmente por Sarlo, Elmir e Todorov, analisar a obra como um relato testemunhal, identificando suas características, virtudes e descontinuidades.

Antes de ingressar especificamente na análise é necessário que se exponha a respeito de Sobibor, o núcleo do livro escrito por Szmajzner. Sobibor foi um dos campos de extermínio da chamada Operação Reinhard, posta em prática pelos nazistas com o objetivo de implementar a chamada "solução final para a questão judaica", a aniquilação da população judaica nos territórios ocupados pela Alemanha durante a Segunda Guerra Mundial. ${ }^{2}$

\footnotetext{
${ }^{1}$ ELMIR, Cláudio Pereira. A palavra como um bisturi. In: PEDRO, Joana Maria; WOLFF, Cristina Scheibe. (Org.). Ge nero, feminismos e ditaduras no Cone Sul. Florianópolis: Ed. Mulheres, 2010. p. 194.

2 ABAL, Felipe Cittolin. Nazistas no Brasil e Extradição: os pedidos de extradição de Franz Stangl e Gustav Wagner em uma análise jurídico-histórica. Curitiba: Juruá, 2014. p. 41.
} 
Em Sobibor, ao contrário do que ocorria nos campos de concentração, apenas poucos judeus eram selecionados para sobreviver e trabalhar dentro do campo, enquanto a grande maioria era enviada imediatamente após a sua chegada para as câmaras de gás, fazendo com que apenas um pequeno número de pessoas tenha sobrevivido ao campo para relatar o que lá ocorria. ${ }^{3}$ Assim, a obra escrita por Stanislaw Szmajzner é de valia para o conhecimento a respeito do campo, seu funcionamento e também das experiências daqueles que sobreviveram.

\section{Além da narrativa}

Apesar do fato de que a parte mais importante de um livro é o seu conteúdo expresso nos capítulos, alguns aspectos alheios à narrativa e que circundam a obra podem servir como instrumentos para a sua análise, desde seu título até as informações da contracapa, perpassando pela escolha da época da publicação, elementos que muitas vezes são deixados de lado pelo leitor, mas que são valiosos para o estudo de um relato autobiográfico como o em tela neste momento.

Em busca de publicar a sua obra Stanislaw Szmajzner entrou em contato com Zevi Ghivelder, que trabalhava na Bloch Editores, entregando a ele o manuscrito do livro que acabara de escrever. Ghivelder designou o jornalista Macedo Miranda para avaliar a obra e este, após a leitura, pronunciou seu posicionamento: "Do jeito que está, é impossível publicar. O livro está cheio de erros de português, mas o conteúdo é fascinante, principalmente por causa da revolta dos judeus confinados no campo de concentração de Sobibor". ${ }^{4}$

Tendo em vista o conteúdo pouco explorado da obra, Ghivelder aceitou publicar o livro mediante a concordância de Szmajzner de que ele fosse reescrito. Não consta nas informações do livro a quem coube reescrevê-lo, porém foi o próprio Ghivelder quem realizou a revisão final. ${ }^{5}$

Inferno em Sobibor: a tragédia de um adolescente judeu foi primeiramente publicado em 1968 e, apesar da fraca recepção pela crítica e pelo público, acabou sendo reeditado em 1979 pela Bloch Editores. As datas das edições não parecem ter sido escolhidas a esmo. Em 1967 foi encontrado no Brasil o nazista Franz Stangl, ex-comandante de Sobibor, extraditado no mesmo ano para a Alemanha após julgamento pelo Supremo Tribunal Federal (STF). Sua descoberta no país gerou repercussão nos jornais brasileiros, ${ }^{6}$ e o livro poderia aproveitar do momento em que o nazista e o campo de extermínio ocupavam espaço nos meios midiáticos.

O mesmo pode ser visto em relação à segunda edição, lançada no ano em que foi julgada no Brasil a extradição de outro nazista que havia trabalhado em Sobibor: Gustav

\footnotetext{
3 Ibid.

4 GHIVELDER, Zevi. Inferno em Sobibor. Revista Morashá. 85. ed., mar./2015. Disponível em: <http://www.morasha.com.br/holocausto/inferno-em-sobibor.html>. Acesso em: 10/07/ 2016.

${ }^{5}$ Ibid.

${ }^{6}$ ABAL, Felipe Cittolin. Nazistas no Brasil e Extradição: os pedidos de extradição de Franz Stangl e Gustav Wagner em uma análise jurídico-histórica. Curitiba: Juruá, 2014.
} 
Wagner, segundo em comando no campo de Sobibor e que teve uma relação pessoal com Szmajzner. O autor, no ano anterior, tinha inclusive se encontrado com Wagner para afirmar que ele era um criminoso. O enfrentamento de Szmajzner com seu algoz foi um fato que gerou a publicação de uma página inteira no jornal Folha de São Paulo. ${ }^{7}$

Mesmo com a atenção da mídia voltada para o caso o livro novamente não obteve um grande número de vendas, e Wagner acabou tendo sua extradição negada pelo STF em 1979, cometendo suicídio pouco tempo depois. Ainda, as décadas em que a obra foi editada coadunam com a afirmação de Winter de que, após as narrativas realizadas sobre a Segunda Guerra e o genocídio judaico, os relatos de sobreviventes surgiram com maior força nas décadas de 1960 e 1970: "by the 1960s and 1970s, that narrative work had done its job; the transition to post-war political stability was complete. There was now room for the victims of the camps to come forward. And come forward they did". ${ }^{8}$

Embora o livro não tenha alcançado a repercussão almejada ele ainda era um motivo de orgulho para Szmajzner. Anos após a publicação, ele revelaria a Richard Rashke, autor de um romance sobre Sobibor que foi adaptado para a televisão, que "meu livro foi a melhor coisa que eu fiz em minha vida". ${ }^{9}$ Tal afirmação vai ao encontro do que expunha Todorov a respeito do caráter dúplice da memória e seus relatos. Se por um lado ela proporciona uma generalização da qual o autor pretende tirar uma lição, por outro, ela serve como um trabalho de psicanálise controlando e marginalizando a dor gerada pela lembrança. ${ }^{10}$

O título do livro de Szmajzner, Inferno em Sobibor: a tragédia de um adolescente judeu, pode não trazer estranheza para o público brasileiro composto em sua maioria por pessoas afeitas à fé e às crenças cristãs. Certamente a experiência de um jovem em um campo de extermínio poderia ser comparada ao sofrimento do inferno em sua concepção dantesca. O que causa curiosidade, porém, é a escolha, ou pelo menos a aceitação, da palavra inferno pelo autor, seguidor da religião judaica, uma vez que a ideia de inferno no judaísmo é diversa daquela existente nas religiões cristãs, como explica Don Ber Pinson:

O conceito judaico sobre o inferno é bastante diferente do que comumente se acredita ser um beco sem saída - uma consequência eternamente dolorosa de uma vida espiritualmente falida. A palavra hebraica "Gehinom" não tem uma tradução exata, mas aproxima-se bastante da palavra "inferno". Gehinon, na verdade, é um processo de restauração e recuperação, não uma condição permanente. A alma que chega ao Gehinom pode ser comparada a uma pessoa que inicia uma terapia, purgando-se da negatividade e preparando-se para enfrentar seu verdadeiro eu. ${ }^{11}$ (Grifos do autor)

\footnotetext{
7 Ibid., p. 88.

8 WINTER, Jay. The Generation of Memory: Reflections on the "Memory Boom" in Contemporary Historical Studies. Canadian Military History, v. 10, n. 3, Summer 2001. p. 61.

9 RASHKE, Richard. Fuga de Sobibor. Porto Alegre: 8inverso, 2011. p. 284.

10 TODOROV, Tvetan. Los abusos de la memoria. Barcelona: Ediciones Paidós Ibérica, 2000. p. 31.

11 PINSON, Dov Ber. Inferno a caminho do céu. Disponível em:

<http://www.chabad.org.br/biblioteca/artigos/aCaminho/home.html>. Acesso em: 23/06/2016.
} 
Assim, o título do livro trata mais de direcionar a obra ao público do que propriamente refletir a vivência do autor dentro de suas crenças, realizando uma adaptação com vistas a tornar mais acessível a ideia que seria transposta durante a narrativa, não podendo se deixar de lado a hipótese de que talvez o título tenha sido uma sugestão dos editores e não uma escolha pessoal do autor.

As primeiras informações do livro são três parágrafos referentes a oferecimento, dedicatória e agradecimento. Szmajzner ofereceu o livro ao povo brasileiro, uma vez que, após a Segunda Guerra Mundial, o autor acabou por se estabelecer na cidade de Goiânia, afirmando que "no Brasil encontrei a paz, a liberdade religiosa e a inexistência de preconceitos raciais. Além de tudo, esta é agora a minha verdadeira pátria". ${ }^{12}$ Já neste primeiro instante é possível denotar uma constante no pensamento do autor, a sua aversão aos nacionais de certos países europeus, especialmente os poloneses, descritos em muitos momentos da obra como tão desprezíveis quanto os nazistas. ${ }^{13}$ Devido à sua experiência, Szmajzner renunciava à sua própria nacionalidade polonesa em prol do país que o recebeu após a guerra e onde ele pôde residir e estabelecer a sua família.

O agradecimento constante foi destinado a João Alberto Magalhães Borges, que auxiliou o autor no relato em português. A dedicatória, por sua vez, voltou-se aos familiares do autor e a "todos aqueles que foram assassinados em Sobibor ou que tombaram na Segunda Guerra Mundial sem estar na frente de batalha". ${ }^{14}$

Antes de iniciar a narrativa do autor, consta um prefácio escrito pelo então senador Pedro Ludovico Teixeira, que possuía um laço de amizade com o escritor, uma vez que o auxiliou em sua chegada a Goiânia, onde adquiriu uma fazenda e permaneceu até o seu falecimento.

\section{O caminho para Sobibor}

O livro de Stanislaw Szmajzner é dividido em 14 capítulos nos quais o autor relata desde a sua infância na Polônia até o momento após a sua fuga de Sobibor e o ingresso em um grupo partisan de resistência à ocupação nazista, tratando-se de um relato autobiográfico como especificado por Alberti:

[...] a identidade entre autor, narrador e personagem é condição sine qua non de uma autobiografia, consubstanciada no pacto autobiográfico: a identidade entre o nome exposto na capa e na folha de rosto (um nome que equivale a uma assinatura) e o nome que o narrador se dá como personagem principal, acrescida na maioria das vezes da indicação, na capa, na folha de rosto, nas orelhas e na contracapa, de que se trata de uma autobiografia. O pacto autobiográfico se dá, então, quando a identidade entre autor, narrador e personagem é assumida e tornada explicita pelo autor, ao contrário do "pacto romanesco", declaração de

\footnotetext{
12 SZMAJZNER, Stanislaw. Inferno em Sobibor: a tragédia de um adolescente judeu. 2. ed. Rio de Janeiro: Bloch Editores, 1979. p. 24.

13 Ibid., p. 292.

14 SZMAJZNER. Op. cit., p. 8.
} 
negação daquela identidade e atestado do caráter de ficção. ${ }^{15}$ (Grifo do autor)

Apesar de não constar nas informações da obra a indicação específica de autobiografia, todos os demais elementos previstos por Alberti são cumpridos, devendo ressaltar, ainda, que o livro fazia parte da "Coleção Depoimento" da Editora Bloch, restando indiscutível o seu caráter autobiográfico.

A obra pode ser dividida em duas partes: a primeira delas, constante de cinco capítulos, relata a vida do autor logo antes da ocupação nazista da Polônia, onde residia, e sua trajetória, passando por guetos judaicos e realizando trabalhos forçados, até chegar ao campo de extermínio de Sobibor, quando se inicia a segunda parte. Das 277 páginas do livro, quase um terço delas, 90 páginas, são dedicadas a esse momento inicial no qual o leitor acompanha o narrador até o destino anunciado no título, o inferno concretizado em Sobibor.

O primeiro capítulo, assim como outros que compõem a obra, inicia-se com uma exposição de caráter histórico a respeito da invasão alemã da Polônia, aparecendo grifada em itálico. Provavelmente as exposições históricas inseridas no começo desses capítulos com o intuito de situar o leitor foram resultado da reescrita do livro realizada com fins de publicá-lo, conforme exposto anteriormente, até mesmo diante do fato de que é perceptível uma quebra de narrativa e estilo literário. O primeiro parágrafo, nitidamente escrito por Szmajzner, é um aviso ao leitor e também uma afirmação da veracidade dos fatos narrados:

De toda a tragédia que envolveu meu povo e minha terra, nada posso
oferecer ao leitor que o faça transportar-se aos floridos jardins de
Varsóvia em busca de um terno romance, ou então aos domínios da
ficção, onde só encontraria fantasias e quimeras. Este relato, frio e
desassombrado, desprovido de adornos literários que poderiam torná-lo
mais ameno, conta a minha história, a verdade do que aconteceu a um
menino de doze anos. Ainda hoje, decorridos tantos e tantos anos,
pergunto-me, muitas vezes, se tudo isso ter-se-ia passado realmente
comigo. ${ }^{16}$

Já desse início podem-se verificar algumas características do relato que é realizado no livro. Primeiramente, o autor firma um acordo com o leitor, o de que ele irá confidenciar a sua história, uma história verdadeira e que ele, como sobrevivente de uma situação extrema pode contar, tornando difícil a tarefa de análise para o investigador, uma vez que o escritor aparece em uma condição de superioridade derivada de sua experiência e do contato com o mistério do mal e do milagre da sobrevivência, como expôs Jay Winter: "The person who suffered knows about a mystery - the mystery of evil and the miracle of survival - and we who listen may thereby enter the mystery and share the miracle. This is a difficult area to investigate". ${ }^{17}$

\footnotetext{
15 ALBERTI, Verena. Literatura e autobiografia: a questão do sujeito na narrativa. Estudos Históricos, v. 4, n. 7, 1991. p. 10-11.

${ }^{16}$ SZMAJZNER, Stanislaw. Inferno em Sobibor: a tragédia de um adolescente judeu. 2. ed. Rio de Janeiro: Bloch Editores, 1979. p. 24.

17 WINTER, Jay. The Generation of Memory: Reflections on the "Memory Boom" in Contemporary Historical Studies. Canadian Military History, v. 10, n. 3, Summer 2001. p. 60.
} 
A segunda característica que pode ser ressaltada é a legitimidade clamada pelo autor ao afirmar que sua narração se afasta de qualquer característica ficcional para contar aquilo que realmente ocorreu ao menino de doze anos, ele mesmo, apoiando-se em sua memória do que ocorreu quase 30 anos antes da publicação do livro, incorrendo o descrito por Beatriz Sarlo:

Quando uma narração memorialística concorre com a história e apóia sua exigência nos privilégios de uma subjetividade que seria sua garantia [...], ela se coloca, pelo exercício de uma imaginária autenticidade testemunhal, numa espécie de limbo interpretativo. ${ }^{18}$

Nessa primeira parte da narrativa, calcada nos fatos que ocorreram antes da operacionalização dos campos de extermínio na Polônia, também pode ser vista a mágoa do autor com os alemães e nazistas através das palavras escolhidas para descrevê-los, podendo ser percebida a subjetividade do relato, destoando da possibilidade de simplesmente encarar os fatos narrados como aquilo que realmente aconteceu, conforme coloca Ângela de Castro Gomes:

[...] está descartada a priori qualquer possibilidade de se saber "o que realmente aconteceu" (a verdade dos fatos), pois não é essa a perspectiva do registro feito. O que passa a importar para o historiador é exatamente a ótica assumida pelo registro e como seu autor a expressa. Isto é, o documento não trata de dizer "o que houve", mas de dizer o que o autor diz que viu, que ouviu, sentiu e experimentou, retrospectivamente, em relação a um acontecimento. Um tipo de discurso que produz uma espécie de "excesso de sentido do real pelo vivido", pelos detalhes que pode registrar, pelos assuntos que pode revelar e pela linguagem intimista que mobiliza. ${ }^{19}$ (Grifos do autor)

Por vezes os poloneses são nominados de polacos, especialmente quando agem de forma a atingir negativamente o autor, enquanto os alemães são chamados, no decorrer da obra, de boches, palavra pouco utilizada na atualidade e que surgiu como um termo pejorativo francês para designar os soldados alemães na Primeira Guerra Mundial. ${ }^{20}$ Esse artifício utilizado pelo autor (de forma consciente ou não) traz consigo a capacidade de criar a antipatia do leitor em relação ao personagem que é narrado, uma vez que é impossível ter qualquer empatia com o "polaco [que] não me conhecia, mas tinha uma espécie de sexto sentido para identificar compatriotas judeus" ou com os boches que fizeram com que sua "pátria [fosse] invadida, dominada e ultrajada". ${ }^{21}$ A própria escolha das palavras já é um indicativo das preferências, visões e experiências do autor.

\footnotetext{
18 SARLO, Beatriz. Tempo passado: cultura da memória e guinada subjetiva. São Paulo: Companhia das Letras; Belo Horizonte: UFMG, 2007. p. 68.

19 GOMES, 2007 apud ELMIR, Cláudio Pereira. A palavra como um bisturi. In: PEDRO, Joana Maria; WOLFF, Cristina Scheibe. (Org.). Ge nero, feminismos e ditaduras no Cone Sul. Florianópolis: Ed. Mulheres, 2010. p. 193.

20 LAROUSSE. Boche. Disponível em: <http://www.larousse.fr/dictionnaires/francais/boche/9978>. Acesso em: 28/06/2016.

21 SZMAJZNER, Stanislaw. Inferno em Sobibor: a tragédia de um adolescente judeu. 2. ed. Rio de Janeiro: Bloch Editores, 1979. p. 39.
} 
Dois momentos narrados nessa primeira parte também devem ser ressaltados. Durante o momento inicial do livro, uma constante segue o narrador: a sua família, colocada em uma posição central e objeto das maiores preocupações e sacrifícios pelo personagem principal. No segundo capítulo, o autor relata uma briga que teve com seu pai quando este se fez passar por católico para pedir comida, colocando que "a cena foi tão horrível e o fato tão aviltante para um judeu que, se ouso inseri-lo nesta narrativa, é porque prometi a mim mesmo, no início desta história, que relataria toda a verdade, por mais chocante que fosse".22 O fato de confessar que chegou às vias de fato com seu próprio pai por estar indignado com sua traição ao judaísmo também possui o condão de gerar credibilidade à narrativa.

Enquanto momentos de glória, heroísmo e destaque podem trazer desconfiança ao leitor, a confissão de uma vergonha, por sua vez, é muito mais crível, seja esta confissão encarada literariamente ou em seu caráter jurídico ou até mesmo religioso. De acordo com o sentimento comum, ninguém confessa um crime que não cometeu a não ser em virtude de tortura ou ameaças, assim como ninguém ingressa no confessionário de uma igreja para pedir absolvição por pecados que não ocorreram. O único motivo que levaria o autor a revelar sua vergonha seria o seu compromisso com a verdade.

O segundo momento relatado quase na sequência é referente a um dos romances que o autor teve mesmo em meio a todo o sofrimento, dor e violência que o cercavam durante a ocupação nazista, sendo que tais relatos aparecem em vários momentos da obra. Ao discorrer a respeito de uma de suas primeiras experiências amorosas, o autor parece abrir mão de sua promessa realizada no início da obra de que realizaria um relato "frio e desassombrado", descrevendo um de seus encontros:

[...] a jovem estendia-me os braços, tateava-me com as mãos pecaminosas e maltratava-me com as filadas unhas, afagando-me num oceano de lascívias e fazendo com que a minha alucinada imaginação passeasse por deliciosos caminhos. ${ }^{23}$

Enquanto certas passagens do livro, por mais chocantes que pareçam, são descritas em poucos parágrafos, ao dissertar sobre sua namorada, Zelde, são ocupadas duas páginas no que pode ser visto como uma estranha seleção para uma obra que se propunha a descrever o inferno. Diante disso, pode-se denotar o desequilíbrio entre os relatos, típico de autobiografias, como esclarece Alberti:

Assim, se alguém se põe a escrever uma autobiografia, é porque tem em
mente fixar um sentido em sua vida e dela operar uma śintese. Sintese
que envolve omissões, seleçãa de acontecimentos a serem relatados e
desequilibrio entre os relatos (uns adquirem maior peso, são narrados
mais longamente do que outros), operacõos que o autor só é capaz de
fazer na medida em que se orienta pela busca de uma significação: busca
essa que lhe dirá quais acontecimentos ou reflexões devem ser omitidos e
quais (e como) devem ser narrados. E essa busca também que prevalece

22 Ibid., p. 63.

23 SZMAJZNER, Stanislaw. Inferno em Sobibor: a tragédia de um adolescente judeu. 2. ed. Rio de Janeiro: Bloch Editores, 1979. p. 71. 
na estrutura do texto, os relatos ganhando sentido à medida que vão sendo narrados, acumulando-se uns aos outros, de modo que a significação se constrói no momento mesmo em que o autor escreve a autobiografia. ${ }^{24}$

Dessa forma, a primeira parte da narrativa do autor pode ser vista como um momento de apresentação do personagem principal em que já são estabelecidas algumas de suas características e são esclarecidos para o leitor os seus afetos (família), desafetos (poloneses e alemães) e as intimidades do próprio autor e personagem principal. A trama constituída de dramas familiares e afeições juvenis é posta em suspensão com o início da segunda parte, com a chegada do autor e seus familiares a Sobibor.

\section{Sobibor, memória e vingança}

A segunda parte da obra de Szmajzner foca-se no período em que esteve preso no campo de extermínio de Sobibor, localizado na Polônia, iniciando com sua chegada e finalizando após a sua fuga, ocorrida quando sucedeu a revolta dos prisioneiros do campo. Esse momento é caracterizado, primeiramente, pelo surgimento dos opositores ao personagem principal, nazistas nominados e que se tornam os vilões da obra, aparecendo na narrativa logo quando da chegada de Szmajzner e seus familiares no campo.

Dois dos nazistas melhor retratados são exatamente o comandante do campo, Franz Stangl, e o segundo em comando no local, Gustav Wagner, os quais, conforme já exposto, foram encontrados posteriormente no Brasil, em datas próximas ao lançamento da primeira e segunda edições do livro. Stangl é descrito por Szmajzner da seguinte forma, quando o viu no desembarque do trem: "trajava calça cinza, característica do Exército alemão, um impecável dólmã branco e um casquete bem posto à cabeça. Atirava com pistola em judeus que estavam desembarcando $[\ldots]^{\prime \prime}{ }^{25}$

Essa lembrança do autor causa certa estranheza. Segundo ele, o caos ocorrido na chegada era tamanho a ponto de impedir a real concepção do que acontecia: "tínhamos o raciocínio embotado pela bulha que se fazia e não pudemos sequer orientar-nos para ver onde estávamos naquele momento, mesmo porque inexistia qualquer ponto de referência". ${ }^{26}$ Uma das únicas fotos existentes de Franz Stangl em Sobibor retrata o nazista a distância, vestido exatamente da maneira descrita por Szmajzner. O fato de ele usar um dólmã branco, por sua vez, era uma característica do ex-comandante de Sobibor. Parece que o autor, nesse instante, mais do que revelar uma lembrança existente acabou por adaptar ao que posteriormente viu, coadunando com Hallbwachs ao colocar que "o passado se distorce para introduzir-se

\footnotetext{
24 ALBERTI, Verena. Literatura e autobiografia: a questão do sujeito na narrativa. Estudos Históricos, v. 4, n. 7, 1991. p. 12.

${ }^{25}$ SZMAJZNER, Stanislaw. Inferno em Sobibor: a tragédia de um adolescente judeu. 2. ed. Rio de Janeiro: Bloch Editores, 1979. p. 115.

${ }^{26}$ Ibid.
} 
coerência". ${ }^{27}$ Ainda, a descrição de que Stangl tenha atirado pessoalmente em pessoas é de difícil comprovação, uma vez que se trata do único relato a respeito de um ato de violência realizado pessoalmente pelo nazista que, na maior parte das descrições, é tido como um burocrata distanciado da vivência no campo. ${ }^{28}$

Wagner, por sua vez, é uma figura central na obra de Szmajzner. Além de ter sido quem selecionou Szmajzner para trabalhar em vez de ser enviado às câmaras de gás, 0 nazista utilizou continuamente de sua perícia como ourives para que fossem produzidas para si joias e adornos. No decorrer do livro, Wagner acaba sendo a personificação de Sobibor e é assim descrito pelo autor:

[...] era um monstro de quase dois metros de altura. De compleição fisica avantajada, devia pesar mais de cem quilos e possúia a força de um touro. Sua peculiaridade principal residia nos excessivamente longos braços, caídos em seu natural até a altura dos joelhos, de maneira absurdamente desproporcional. Tinha também grave deformidade num dos ombros, com um deles bem mais curto que o outro, o que acarretava um modo exce ntrico de caminhar, sempre tombado para a direita. Além disso, andava constantemente a balançar o corpo, oscilando-se de um lado para o outro, o que lhe concedia apare ncia de verdadeiro orangotango. Seu rosto assemelhava-se a uma caveira talhada em granito, tal a rigidez das formas. Os olhos eram de um verde tão carregado que chegavam a magnetizar quem os olhasse fixamente. Não obstante, eram apagados como os de um peixe morto, sem brilho, sem vivacidade. ${ }^{29}$

A descrição realizada pelo autor nesse ponto pouco tem a ver com a realidade. Wagner era um homem alto e forte que, certamente, aos olhos de um jovem amedrontado de 15 anos, poderia parecer um monstro. A sua comparação com um orangotango e a inclusão de uma deformação física, porém, em nada refletem a verdadeira imagem de Wagner, servindo mais como um instrumento de desumanização do nazista, que, na narrativa, seria um monstro, um animal ou um ser disforme e não um ser humano capaz de cometer atrocidades.

Gize-se que tal constatação não tem por condão desacreditar o autor e suas memórias, porém cabe a quem realiza a análise de um texto autobiográfico constatar tanto os fatos que possuem outras bases para afirmação quanto as narrativas que se contrapõem ou contradizem outras fontes, uma vez que, como expõe Cláudio Elmir, "no caso específico de um relato autobiográfico, sucumbir à tentação de analisar a narrativa como se ela se encerrasse nela mesma pode se tornar, metodologicamente, um caminho seguro para o precipício". ${ }^{30}$ Dessa forma, as inconsistências da memória também devem ser apontadas.

No decorrer da segunda parte do livro, Szmajzner narra como foi aos poucos tomando contato com o funcionamento e o que realmente ocorria em Sobibor. Um dos responsáveis por

\footnotetext{
27 HALLBWACHS, 1990 apud SARLO, Beatriz. Tempo passado: cultura da memória e guinada subjetiva. São Paulo: Companhia das Letras; Belo Horizonte: UFMG, 2007. p. 49.

28 ABAL, Felipe Cittolin. Nazistas no Brasil e Extradição: os pedidos de extradição de Franz Stangl e Gustav Wagner em uma análise jurídico-histórica. Curitiba: Juruá, 2014. p. 63.

29 SZMAJZNER, Stanislaw. Inferno em Sobibor: a tragédia de um adolescente judeu. 2. ed. Rio de Janeiro: Bloch Editores, 1979. p. 124.

30 ELMIR, Cláudio Pereira. O caso Binjamin Wilkomirski: a dupla invenção da memória. Anos 90 . Porto Alegre, v. 15, n. 28 , p. 41-55, dez./2008. p. 47.
} 
informar-Ihe o que ocorria no chamado Campo III, onde ficavam as câmaras de gás, foi um amigo seu que reconheceu após a sua chegada, Abrão, que enviava a Szmajzner bilhetes através de um guarda ucraniano esclarecendo a respeito da morte de todos os que iam até essa parte de Sobibor. O conteúdo de um desses bilhetes (na verdade uma carta) é relatado pelo autor e ocupa uma página e meia, utilizando-se de aspas em sua narrativa, levando o leitor a crer que se trata ipsis literis o escrito pelo remetente. ${ }^{31}$

É perfeitamente verossímil que o autor recordasse do teor geral da mensagem recebida após quase três décadas, porém registrar linha por linha o escrito pelo seu amigo não parece possível e, retirando a necessidade de se conferir extrema legitimidade ao relato, não existe outro motivo pelo qual o autor desejaria outorgar a si mesmo tal capacidade de recordação. Coaduna também com essa constatação o relato de outra mensagem recebida pelo autor, em que Abrão explanava o funcionamento do Campo III e teria exposto que, após as vítimas serem colocadas nas câmaras de gás, um membro da SS "abria a clarabóia, atirava uma lata de gás sobre a compacta massa de condenados e voltava a fechá-la. O gás era o mortífero Ciclon-B (sic)". ${ }^{32} \mathrm{Na}$ realidade o famigerado Zyklon B não foi utilizado em Sobibor, onde o assassinato dos prisioneiros era realizado com monóxido de carbono gerado por um motor de tanque existente ao lado das câmaras de gás. A questão do uso do Zyklon B foi alvo de diversas matérias jornalísticas após a Segunda Guerra Mundial, dando a impressão de que ele teria sido utilizado em todos os campos, porém essa não é a realidade, tratando-se, provavelmente, de uma adaptação do autor a informações obtidas posteriormente.

Todas as descrições acerca das pessoas que estavam em Sobibor, sejam prisioneiros ou nazistas, assim como dos procedimentos realizados e demais informações encaixam-se no exposto por Beatriz Sarlo como primado do detalhe, conferindo ao texto um caráter de verossimilhança que, por sua vez, deve ser visto como distinto da verdade: "Sem dúvida, a verdade está no detalhe. Mas, se não é submetido à crítica, o detalhe afeta a intriga por sua abundância realista, isto é, por seu aspecto verossímil mas não necessariamente verdadeiro". ${ }^{33}$

Enquanto o primeiro instante do relato do autor sobre o tempo vivido em Sobibor pode ser encarado como uma transição, como o momento em que ele passa de um profano, desconhecedor dos mistérios do campo, para um iniciado, aquele que detém o conhecimento e que se encarrega de transmiti-lo para os demais, o segundo instante mostra outra transmutação do personagem principal/autor. De uma vítima, alvo de violências e humilhações, Shlomo, o adolescente de 15 anos, passa a ser um líder, herói e sobrevivente.

Com a chegada de um grupo de prisioneiros soviéticos liderados por Sasha Pechersky (Sasza Pieczerski na escrita de Szmajzner), começaram preparativos para uma revolta dos prisioneiros com o objetivo de fugir de Sobibor e evitar o destino de todos dentro do campo, as câmaras de gás. O Politruk, como é chamado pelo autor, organizou junto a outros prisioneiros

\footnotetext{
31 SZMAJZNER. Op. cit., p. 150-151.

32 SZMAJZNER, Stanislaw. Inferno em Sobibor: a tragédia de um adolescente judeu. 2. ed. Rio de Janeiro: Bloch Editores, 1979, p. 189.

33 SARLO, Beatriz. Tempo passado: cultura da memória e guinada subjetiva. São Paulo: Companhia das Letras; Belo Horizonte: UFMG, 2007. p. 52.
} 
o modo como a revolta seria realizada, sendo que o personagem principal é sempre inserido como um dos líderes da revolta, apesar de sua pouca idade.

Duas questões devem ser grifadas quanto à última parte da narrativa. Primeiramente, o destaque que o autor dá a si mesmo no decorrer do relato. Após a chegada dos soviéticos, poderia se esperar que a centralidade do movimento fosse deslocada às suas ações, uma vez que eles foram essenciais à ocorrência da revolta, porém a escrita mantém-se atrelada ao personagem principal, o próprio autor, como parte imprescindível a todos os acontecimentos. Nesse instante é importante inserir o pensamento de Todorov sobre uma das razões do culto à memória:

[...] un antiguo combatiente, un antiguo miembro de la Resistencia, un antiguo héroe no desea que su pasado heroísmo sea ignorado, algo muy normal después de todo. Lo que sí es más sorprendente, al menos a primera vista, es la necesidad experimentada por otros individuos o grupos de reconocerse en el papel de víctimas pasadas, y de querer asumirlo en el presente. ${ }^{34}$

No caso de Szmajzner pode-se denotar que a importância da memória, seguindo as linhas de Todorov, alcança os dois âmbitos. De um lado, o autor deseja imortalizar a sua importância como um herói, sobrevivente de um campo de extermínio e, posteriormente, membro da resistência. De outro, foi uma vítima dos horrores nazistas, posição da qual busca se libertar e redimir com seus atos de irresignação.

A segunda questão que chama a atenção na leitura é que, mesmo sendo reconhecida a importância da "liderança intrépida de Sasza Pieczerski, o Politruk", ${ }^{35}$ em diversos momentos pode ser percebida a ausência do soviético na narrativa, como se ele desaparecesse em instantes essenciais da revolta. Essa omissão do autor provavelmente não é desprovida de intenção. Após a revolta, vários judeus, entre eles Szmajzner, os soviéticos e o Politruk, conseguiram sobreviver e se reagruparam em uma floresta. Durante a madrugada os soviéticos fugiram sozinhos, deixando para trás os demais, um ato considerado por Szmajzner como uma traição difícil de perdoar. Anos depois, quando entrevistado por Richard Rashke, Szmajzner ainda demonstrava sua mágoa com Pechersky, além de reconhecer que seu papel de liderança não havia sido tão importante quanto o retratado. Perguntado sobre Sasha respondeu:

Eu o respeito [...] Sem ele não teríamos sobrevivido. Mais do que isso não posso falar. Eu não posso falar sobre alguém que fez, digamos, dez coisas boas e talvez uma ruim. Não seria justo. [...] Os líderes são Feldhendler e Pechersky. Meu papel foi pequeno. Eu peguei os rifles. ${ }^{36}$

Conseguindo escapar com vida, a realidade de Szmajzner era diferente da dos demais que estavam em seu grupo. "Fui o único a escapar para contar a História do Campo de

34 TODOROV, Tvetan. Los abusos de la memoria. Barcelona: Ediciones Paidós Ibérica, 2000. p. 54.

35 SZMAJZNER, Stanislaw. Inferno em Sobibor: a tragédia de um adolescente judeu. 2. ed. Rio de Janeiro: Bloch Editores, 1979. p. 265.

36 RASHKE, Richard. Fuga de Sobibor. Porto Alegre: 8inverso, 2011. p. 286. 
Extermínio de Sobibor", relata o autor. O final de seu livro, porém, não é o fim de sua história. O autor não termina a obra com um ponto final, mas sim com o prelúdio do que ocorreria posteriormente: "Meu obstinado desejo ainda não se eclipsara. Agora, queria esquecer tudo aquilo e pensar apenas na vendetta" (grifo no original). ${ }^{37}$

Após a sua fuga, Szmajzner passou a lutar ao lado da resistência, mas esta não seria sua maior ação para concretizar seu desejo de vingança. Depostas as armas e estabelecida sua vida no Brasil, ele ainda permanecia com suas lembranças a respeito do que havia ocorrido em Sobibor e suas memórias serviriam como um meio de obter sua vendetta através da publicação de sua autobiografia.

Se de um lado sua obra serviria como uma lição, um alerta para que os horrores sofridos não mais se repetissem, e como um trabalho de autoanálise frente às humilhações e agressões sofridas pelo autor, de outro, ela toma a forma de uma vingança pessoal, obtida através da rememoração dos crimes cometidos pelos seus algozes.

O olvidamento é a maior benesse que um criminoso pode receber. Através do esquecimento suas ações são apagadas, desaparecendo lentamente com o passar do tempo. É nesse ponto que a memória dos sobreviventes, daqueles que foram atingidos pelos atos criminosos, toma ainda mais uma função: a de vingança. Vingança pessoal e também daqueles que não sobreviveram para poder contar suas histórias. Assim, a publicação da autobiografia de Szmajzner apresenta-se como um ato de retaliação, onde todos os nomes dos nazistas que trabalharam em Sobibor e que tiveram contato com o autor estão expostos no livro de forma que seus atos não fossem esquecidos. A revolta de Sobibor não havia terminado em 1943.

\section{Considerações finais}

Todorov expõe que quando um indivíduo ou grupo vivem acontecimentos de natureza excepcional ou trágica surge o dever de recordar e de testemunhar. ${ }^{38}$ Szmajzner abraçou o seu dever e suas memórias renderam uma obra que compensa uma eventual falta de qualidade literária com uma torrente de sentimentos que só podem ser transmitidos por aqueles que vivenciaram uma situação extrema como o genocídio judeu. Se determinados fatos podem ser desacreditados quando colocados diante de outras fontes, não se pode duvidar dos sentimentos do autor ou da veracidade da sua visão sobre o ocorrido.

Este artigo não possui o condão de discordar ou tirar legitimidade do relato de Szmajzner, apesar do risco de ser encarado desta forma, como também alertou Todorov:

La carga emocional de cuanto tiene que ver con el pasado totalitario es enorme, y quines lo han vivido desconfian de los intentos de clarificación, de los llamamientos a un análisis previo a la valoración. Sin embargo, lo que la memoria pone en juego es demasiado importante para dejarlo a merced del entusiasmo o la cólera. ${ }^{39}$

\footnotetext{
37 SZMAJZNER. Op.cit., p. 299-300.

38 TODOROV, Tvetan. Los abusos de la memoria. Barcelona: Ediciones Paidós Ibérica, 2000. p. 18.

39 Ibid., p. 15.
} 
Assim, o objetivo principal foi o de encarar o relato autobiográfico como uma transposição da memória para a palavra escrita, vendo-o com todas as virtudes e os defeitos que a memória pode possuir diante do inevitável processo de seleção gerado, conservando algumas partes e deixando de lado outras ${ }^{40}$ sendo necessário, portanto, que se submeta essa forma de testemunho a um escrutínio metodológico. ${ }^{41}$

É importante expor, neste momento, a forma descrita por Todorov para que se defina o que denomina como bom uso da memória: "Una manera - que praticamos cotidianamente de distinguir los buenos usos de los abusos consiste en preguntarnos sobre sus resultados y sopesar el bien y el mal de los actos que se pretenden fundados sobre la memoria del pasado". ${ }^{42}$ Diante dessa forma de se distinguir os bons usos dos abusos da memória, pode-se afirmar que Szmajzner realizou em sua obra um bom uso da memória, uma vez que seu livro serve como uma forma de buscar a justiça, retratando os algozes e as vítimas, e deixar viva a memória do passado para que os horrores do genocídio judeu durante a Segunda Guerra Mundial não venham a se repetir no futuro.

No dia 4 de março de 1989, o Jornal do Brasil publicou o obituário de Stanislaw Szmajzner, no qual ele foi descrito como "autor do livro Inferno em Sobibor". Mesmo diante da morte do seu autor, a obra sobreviveria. Enquanto as demais notas de falecimento contaram com poucas linhas, a descrição da vida de Szmajzner ocupou duas colunas e foi destacada com a foto do sobrevivente com a legenda "O herói de Sobibor". Shlomo e suas memórias nunca perecerão para aqueles que conhecem sua história. Sua vingança estava completa.

Felipe Cittolin Abal: Doutor em História pela Universidade de Passo Fundo/RS. Graduado em Ciências Jurídicas e Sociais, especialista em Direito do Trabalho e mestre em História pela mesma instituição. É professor na Faculdade de Direito da Universidade de Passo Fundo/RS.

\footnotetext{
40 TODOROV, Tvetan. Los abusos de la memoria. Barcelona: Ediciones Paidós Ibérica, 2000, p. 16.

${ }^{41}$ SARLO, Beatriz. Tempo passado: cultura da memória e guinada subjetiva. São Paulo: Companhia das Letras; Belo Horizonte: UFMG, 2007. p. 46.

42 TODOROV. Op. cit., p. 30.
} 